\title{
Correction to: Gender-Based Differences in Abdominal Aortic Aneurysm Rupture: A Retrospective Study; Review of COVID-19 Vaccines Approved in the United States of America for Emergency Use; Review of COVID-19 Variants and COVID-19 Vaccine Efficacy: What the Clinician Should Know?
}

\author{
Rachana Vanaparthy
}

Gender-Based Differences in Abdominal Aortic Aneurysm Rupture: A Retrospective Study, Journal of Clinical Medicine Research, 2020;12(12):794-802. doi: 10.14740/jocmr4376

Review of COVID-19 Vaccines Approved in the United States of America for Emergency Use, Journal of Clinical Medicine Research, 2021;13(4):204-213. doi: 10.14740/jocmr4490

Review of COVID-19 Variants and COVID-19 Vaccine Effica- cy: What the Clinician Should Know? Journal of Clinical Medicine Research, 2021;13(6):317-325. doi: 10.14740/jocmr4518

The authors of the 3 articles above would like to make the following change:

The affiliation for author "Rachana Vanaparthy" should read "Physicians for American Health Care Access, Philadelphia, PA, USA", instead of "Department of Medicine, Oregon Health and Science University, Portland, OR, USA".

Manuscript submitted July 7, 2021, accepted July 22, 2021

Published online July 28, 2021

Physicians for American Health Care Access, Philadelphia, PA, USA.

Email: mail2rachanav@gmail.com 